\title{
A Longitudinal Study of Factors Associated with Intentions to Leave among Newly Graduated Nurses in Eight Advanced Treatment Hospitals in Japan
}

\author{
Maki TEI-TOMINAGA ${ }^{1 *}$ and Akiko MIKI $^{2}$
}

\author{
${ }^{1}$ Department of Nursing, Hyogo University of Health Sciences, 1-3-6 Minatojima, Chuo-ku, Kobe 650-8530, Japan \\ ${ }^{2}$ Department of Psychiatric and Mental Health Nursing, University of Tsukuba, Ibaraki, Japan
}

Received October 27, 2008 and accepted February 26, 2009

\begin{abstract}
This study aimed to examine the factors associated with intentions to leave among newly graduated nurses (NGNs), using a longitudinal design. We distributed self-administered questionnaires (to be returned anonymously) to all the NGNs $(n=567)$ in nine advanced treatment hospitals in Japan on two separate occasions (Time 1 and Time 2, which were approximately 6 months apart). The questionnaire items addressed individual attributes, employment and organizational characteristics, and subjective health, and also included the 22-item Job Content Questionnaire, a scale of intentions to leave, and a novel 21-item job readiness scale. The data from 301 NGNs who had participated in both questionnaire instances was used, and a hierarchical multiple regression analysis was conducted to investigate the factors associated with intentions to leave. The results showed that while psychological distress was a more important predictor of intentions to leave than was cumulative fatigue at Time 1, cumulative fatigue was a more important predictor at Time 2. Among the job stressors, a lack of coworker support consistently led to increased intentions to leave, while a lack of supervisor support had a greater impact on intentions to leave at Time 1. "Being personally suited for nursing work", which was one of the job-readiness subscales, was found to independently and consistently influence intentions to leave. Our study findings revealed the predictors of intentions to leave among NGNs early in their careers in Japan.
\end{abstract}

Key words: Intentions to leave, Job stressors, Subjective health status, Newly graduated nurses, Job readiness

\section{Introduction}

Recently in Japan, the demand for nurses has been increasing in various areas because of a medical reform bill and government amendments to the medical service payment structure. The Ministry of Health, Labor and Welfare estimates that there will be a shortage of 15,900 nurses by $2010^{1)}$.

As the need for nurses is increasing, the early resignation of newly graduated nurses (NGNs) is becoming a critical issue in Japan. According to a research study concerning NGNs, $18.6 \%$ of the 1,219 hospitals surveyed responded that "the early resignation of NGNs will

*To whom correspondence should be addressed.

E-mail: temakimaki@huhs.ac.jp increase in the near future", while $42 \%$ of advanced treatment hospitals $(n=66)$ had the same response ${ }^{2}$.

High employee turnover negatively affects organizations through the cost of recruitment, reduced productivity, and physical and psychological burdens on employees $^{3-5)}$. Regarding nurses in particular, a previous study indicated the high cost of the turnover of nurses who had been employed for less than one year ${ }^{6}$. The rapid turnover of NGNs also results in an escalating shortage of veteran nurses ${ }^{7}$.

Employees' intentions to leave are the greatest predictor of turnover ${ }^{4,8,9)}$. Coomber and Barriball indicated in their literature review that stress and leadership issues continue to exert influence on nurses' intentions to leave, although these results were not always consistent ${ }^{10)}$. Regarding intentions to leave among NGNs, there is an 
indication that the effect of psychological distress is related to job stressors ${ }^{11,12)}$. Several studies have revealed the effect of job stressors on nurses' psychological and physical health ${ }^{13-17)}$. Meanwhile, a previous survey also reported that the number of NGNs who resign from hospitals due to health problems, especially psychological health problems, will increase in the near future ${ }^{11)}$.

Kramer (1974) indicated that a lack of job readiness can result in a "reality shock", which becomes a factor in turnover as well as in negative feelings about their career choice ${ }^{18)}$. Recently, the Japanese government has repeatedly reexamined and revised nursing standing orders, with the purpose of reducing the duration of hospitalizations. Among the hospitals that introduced the new nursing standing orders, in the one that charges the highest medical fees, hospital bed utilization was mostly by acutelyill patients, and thus working in the hospital required high levels of ability among its nurses. Additionally, technological advancements in Japan such as the electronic medical chart have brought various changes in medical work conditions, and caused nurses' work to become more demanding and complicated. Meanwhile, the duration of practical training for student nurses is becoming more limited. Two factors related to this limited condition are: the introduction of the integrated curriculum (which is a system for requiring student nurses to reach the national examination qualifications to become a registered nurse, public health nurse, etc. in a limited time of four years); and ethical and safety considerations such as the risk of malpractice suits due to a student's insufficient knowledge and technical skills when offering advanced medical treatment to patients in acute stages ${ }^{2}$. This situation may result in a bigger discrepancy between the competency of NGNs and workplace requirements, and is a likely contributor to the increase in nurse resignations.

However, it was unclear which of these factors have the greatest influence on NGNs' intentions to leave during their careers. Most of the previous studies on nurses' intentions to leave were cross-sectional studies that examined the work environment including job stress $\left.{ }^{13}, 19\right)$ and psychological distress ${ }^{12)}$, stressful life events ${ }^{20)}$, anticipatory and organizational socialization ${ }^{21)}$, commitment and job satisfaction ${ }^{22)}$, and motives in the selection of occupation $^{23)}$. There was one study that examined whether burnout was a contributing factor in NGNs' early resignation after three months of employment; however, the results indicated that burnout may not directly contribute to turnover ${ }^{7}$.

In order to intervene against the early resignation of NGNs during their career, longitudinal studies are needed to examine the influence of the above factors on intentions to leave. Thus, in this study, we conducted an investigation using a longitudinal design to examine the effect of job stressors, subjective health status (psychological distress and cumulative fatigue), and job readiness as factors associated with intentions to leave among NGNs. The results may help hospital employers and managers to understand ways to prevent NGNs' early resignation.

\section{Participants and Methods}

In this study, we defined "newly graduated nurses (NGNs)" as registered nurses who had been in their current job for less than twelve months and had no prior nursing work experience since graduating from a nursing education institution. We defined "early resignation" as leaving one's first job at a medical institution within one year after starting to work.

\section{Participants}

A previous study reported that the turnover ratio of nurses differs according to the hospital's location and its regulations regarding nursing staff and shifts ${ }^{24}$. Therefore, we used a cluster sampling method. Out of 148 advanced treatment hospitals in Japan, most of which were university hospitals listed on the website of the University Hospital Medical Information Network, we selected 34 hospitals, randomized by location. Then we asked the director of the nursing services department in each hospital for their cooperation in this research. Among the nine hospitals that agreed to participate, one is located in a large, government ordinance-designated city, seven are located in medium-sized cities with a population between 100,000 and 500,000, and one other hospital is located in a small-sized city with a population of less than 100,000. Also, about 30\% of these hospitals had recently introduced new nursing staff and shift regulations, while the remainder were making plans to do so.

\section{Ethical considerations and data collection}

Approval for this study was obtained from the institutional ethics committee at the University of Tsukuba (\#360). Participating nurses were not required to sign consent forms; their returning the questionnaire implied consent. Participants were informed about the voluntary nature of participation and assured of confidentiality in the handling of data.

We distributed the self-administered questionnaires (to be returned anonymously) to the participants on two separate occasions: the first time was between June and August 2007 (Time 1), and the second time was between November 2007 and January 2008 (Time 2); both had been indicated as times of the year when there tended to be an increase in intentions to leave among $\mathrm{NGNs}^{11,12)}$. The questionnaires were distributed through the hospitals' nursing departments to their NGNs on staff, and they were 
collected within a few weeks.

Out of the 567 NGNs in the nine hospitals, 414 (73\%) and $458(81 \%)$ participants returned their completed questionnaires at Time 1 and Time 2, respectively. After eliminating those with incomplete data (missing or incomplete answers) and the data from one hospital that had some distribution problems, we analyzed the data from the 301 NGNs who had returned fully-completed data, both at Time $1(n=377)$ and Time $2(n=439)$ (the final response rate was $53 \%)$. About $93 \%(\mathrm{n}=279)$ of the final participants were female, and the average age of these female nurses was $22.6(\mathrm{SD}=2.71)$.

We examined the differences in demographic characteristics between the 301 study participants and the 76 respondents who had incomplete data. The results of this comparison showed that there were no significant differences concerning employment and individual characteristics, except for residential style. The 76 respondents were significantly $(p<0.05)$ more likely to be living alone than were the 301 participants.

\section{Measures}

For the theoretical background of the questionnaire, we referred to the conceptual framework of a previous study that identified factors occurring during three stages of NGNs' transition into the workplace: factors which occurred prior to starting work, factors which occurred when the work began, and factors associated with changes in the work situation (work adjustment factors) which influenced outcomes such as intentions to leave. There are also various individual and organizational factors at each stage which influence the outcomes ${ }^{21)}$.

The questionnaires used at Time 1 and Time 2 both consisted of items concerning factors in the three stages of NGNs' transition into the workplace. For the factors in the pre-work stage, the questions addressed individual attributes (sex, age, marital status, educational level, and residential status), and scale items of job readiness (see "Job Readiness Scale"). The questions also assessed employment characteristics (having personal sentiment toward or association with the current hospital where they work, use of scholarships at current hospital, desired ward, shift work with night shifts, frequency of night shifts per month, average working hours per week, and frequency of working on days off per month), organizational characteristics (size of the hospital's location city, bed capacity of the hospital, number of nurses on staff at the hospital, conditions of the break facilities and amount of permitted rest time in the hospital, average time before the introduction of night shifts after starting work, and mental health education as a measure for preventing the early resignation of NGNs), and scale items for job stres- sors to assess the factors in the beginning-work stage (see "Job Stressors Scale"). Additionally, the questionnaires included two scale items for health status (psychological distress and cumulative fatigue) as work adjustment factors which influence the outcomes (see "Subjective Health Status"), as well as scale items for intentions to leave as an outcome variable (see "Intentions to Leave").

\section{Job Readiness Scale}

Job readiness for nursing implies the clinical, professional, and interpersonal skills and knowledge that NGNs need when they start to work in a medical setting. Recently in Japan, nurses' work is becoming more demanding and complicated because of various changes in medical work. In addition, with the increasing number of college-educated nurses whose practical nursing experience is limited, the competency of NGNs has been decreasing $^{2)}$.

Since there were no existing scales to assess the readiness of NGNs to work in their medical profession, we developed a novel 21-item job readiness scale. To create item pools for the job readiness scale, we referred to a previous government report and a related study ${ }^{25,26)}$. We also conducted individual interviews with the directors of the nursing service departments of two hospitals. As a result, we developed 21 job readiness questionnaire items which are related to NGNs' job readiness: skills, basic knowledge, practical clinical expertise, and attitude as a registered nurse. These items were assessed using a four-point response scale and were scored with Likerttype scoring (1: I totally disagree; 2: I disagree; 3 : I agree; 4: I totally agree). To account for common factors among the 21 readiness items, and to assess for construct validity, we conducted a principal component factor analysis. Following the analysis, four factors emerged. We categorized the four factors as "basic nursing skills and abilities", "interpersonal relationships", "practical clinical expertise and confidence", and "being personally suited for nursing work", and used these as our job readiness subscales (see Appendix).

The higher the total score, the more job readiness the participant had. Since job readiness is a factor in the prework stage, we included this scale in the questionnaire at Time 1 only. The Cronbach alphas of the job readiness subscales were $0.62-0.79$.

\section{Job Stressors Scale}

To measure job stressors, we used a self-administered questionnaire, the Job Content Questionnaire (JCQ) ${ }^{27)}$, which was developed by Karasek and demonstrated for validity in nursing-related studies ${ }^{14,17)}$. We used the 22 item Japanese version of the JCQ ${ }^{28)}$, which has been confirmed as reliable and valid for Japanese workers ${ }^{27,28)}$. 
Karasek's Job Strain model (Job Demand-Control Model) identified psychosocial work constraints, such as high psychological job demands and low decision latitude, which have pernicious effects on physical and mental health ${ }^{27)}$. The JCQ-22 includes question items on "skill discretion", "decision authority", and "psychological demand", which are indicators of the above work constraints. Additionally, the JCQ-22 includes question items on "supervisor support", and "coworker support", both of which are expected to moderate the effect of job strain. There are four possible answers to each question: "strongly disagree", "disagree", "agree", and "strongly agree". Each item was scored using the JCQ-22 scoring method, and then computed according to the JCQ-22 user's guide $^{28)}$. In this study, we used combined scores for "skill discretion" and "decision authority" to indicate each participant's level of "job control", thus bringing the total number of variables to four ("job control", "psychological demand", "supervisor support", and "coworker support").

Subjective health status

General health questionnaire

Psychological distress was assessed using the Japanese version of the 12-item General Health Questionnaire (GHQ-12), which has demonstrated high concurrent validity, internal consistency, and reliability in studies of Japanese workers ${ }^{29,30)}$. Participants were asked whether they had recently experienced particular symptoms or exhibited behavior related to depression or anxiety. The GHQ-12 items were scored using 0-1-2-3 Likert scoring in order to assess the impairment level. The higher the total score, the more psychological distress the participant had.

Cumulative fatigue

The signs of cumulative fatigue experienced by the study participants were assessed using the 13-item Cumulative Fatigue Index (CF-13), which was developed by the Japanese Ministry of Health, Labour and Welfare as a "self-checklist of fatigue accumulation" ${ }^{11}$. Participants were asked whether they had recently experienced particular symptoms related to cumulative fatigue (e.g., "I get tired a lot easier than before", "I feel fatigued when I wake up in the morning"). Responses were scored with a three-point Likert-type scale. The higher the total score, the more cumulative fatigue symptoms the participant had. We used the scores from Time 1 and the mean scores from Time 1 and Time 2 as independent variables.

\section{Intentions to Leave}

Intentions to leave were assessed using a 6-item scale previously developed by Tei and Yamazaki (2003) that has demonstrated high internal consistency and reliability in studies of Japanese IT workers ${ }^{32,33)}$. The items assessed the participant's thoughts and behaviors related to resignation from their job at their present medical institution ("I am fed up with my current hospital job and am earnestly gathering information to find a new job", "I would quit my job at this hospital without a second thought", "If I found another job with conditions that suited me, I think I would quit my job immediately", "I am so fed up with my job that I might not be able to endure it any longer", "I am fed up enough with my job to consider being intentionally absent or late for work", "I have talked seriously with my family or close friends about quitting or changing my job"). Responses were scored using a four-point Likert-type scale. The higher the total score, the stronger was their intention to leave.

\section{Data analysis}

First, we calculated descriptive statistics and correlation coefficients for all the independent variables and the intentions to leave at Time 1 and Time 2.

Concerning the sufficient sample size for multiple linear regression analysis, it is assumed that at least 20 cases per independent variable are necessary ${ }^{34)}$. Since our sample size satisfied this condition, we conducted a hierarchical multiple regression analysis for each outcome variable (at Time 1 and Time 2) in an attempt to determine the factors associated with intentions to leave, in reference to the conceptual framework of a previous study ${ }^{21)}$.

First, as the factors which occurred prior to starting to work, individual attributes and four job readiness subscales were added to the equations of intentions to leave at Time 1 (Model 1). Next, as the factors which occurred when the work began, the four JCQ-22 variables were entered into the equations as well as the variables of employment and organizational characteristics that showed a significant association with intentions to leave at Time 1 (Model 2). Last, as the work adjustment factors which influenced outcomes, two variables of subjective health status at Time 1 (GHQ-12 and CF-13) were entered into the equations (Model 3).

As shown in Model 1 for "Time 2 intentions to leave", as factors which occurred prior to starting to work, individual attributes and four job readiness subscales were added to the equations of intentions to leave at Time 2 . Next, as factors which occurred when the work began, each mean score for the four JCQ-22 variables at Time 1 and Time 2 was entered into the equations, as well as the employment and organizational characteristics that showed a significant association with intentions to leave at Time 2 (Model 2). In addition, as work adjustment factors which influenced outcomes, the two mean scores for subjective health status variables (GHQ-12 and CF-13) at Time 1 and Time 2 were entered into the equations (Model 3). Last, the score for "Time 1 intentions to leave" was entered into the equations as an independent variable (Model 4). The statistics package used was SPSS 15.0J. 


\section{Results}

Table 1 shows a summary of the participants' individual attributes and employment and organizational characteristics. Forty-two percent of the participants had at least a college degree (or higher) in nursing. About 19\% indicated that they were working for hospitals for which they had no personal sentiment and $70 \%$ were working in their desired ward position. Although it is not specified in the table, it should be noted that $44 \%$ were working more than $51 \mathrm{~h}$ a week, which means they did more than $44 \mathrm{~h}$ of overtime work on a monthly basis. However, $71 \%$ did not work on their allocated days off.

Table 2 shows the descriptive statistics, Cronbach alphas, and results of $t$-tests of each variable at Time 1 and Time 2. Concerning subjective health status and intentions to leave, the mean scores of the GHQ-12 at Time 2 were significantly decreased $(p<0.001)$, while those of intentions to leave were significantly increased at Time $2(p<0.001)$.

Table 3 shows the correlation coefficients for independent variables associated with intentions to leave at Time 1 and Time 2. Each of the variables of subjective health status at Time 1 and Time 2 was significantly correlated with all of the job readiness subscales. In terms of the subscales of job stressors assessed at Time 1, job demand, supervisor support, and coworker support had significant correlation coefficients with both of the subjective health variables.

Table 4 shows the results of the hierarchical multiple regression analysis for "Time 1 intentions to leave". In Model 1, "Time 1 intentions to leave" scores were significantly higher among those who scored lower for "interpersonal relationships" and "being personally suited for nursing work". The adjusted R2 score was 0.394. When the variables of factors which occurred when the work began (employment and organizational characteristics, and the four JCQ-22 subscales for Time 1) were entered into the equations of "Time 1 intentions to leave" (Model 2), a hospital capacity of fewer than 500 beds, "supervisor support", and "coworker support" scores became significant. The adjusted R2 score became 0.508 . When the variables of work adjustment factors (the two subjective health status variables: GHQ-12 and CF-13) were added to the equations of "Time 1 intentions to leave" (Model 3), both of the subjective health status variables became significant, while "job control" also became significant. The adjusted R2 score became 0.553. The outcome variable "Time 1 intentions to leave" explained $39 \%, 51 \%$, and $55 \%$ of the variance in Models 1,2 , and 3 , respectively.

Table 5 showed the results of the hierarchical multiple regression analysis for "Time 2 intentions to leave". In Model 1, "Time 2 intentions to leave" scores were sig- nificantly higher among those who scored lower for "being personally suited for nursing work". The adjusted R2 score was 0.260 . When the variables of factors which occurred when the work began (employment and organizational characteristics, and each mean score of the JCQ-22 subscale) were entered into the equations of "Time 2 intentions to leave" (Model 2), a hospital capacity of fewer than 500 beds, "break facilities and amount of permitted rest time in the hospital", "job control", and "coworker support" became significant. The adjusted R2 score became 0.414 . When the variables of work adjustment factors (each mean score of subjective health status: GHQ-12 and CF-13) were added to the equations of "Time 2 intentions to leave" (Model 3), the mean scores of the CF-13 were found to be significant, while the significance of the "break facilities and amount of permitted rest time in the hospital" disappeared. The adjusted R2 score became 0.467 . When "Time 1 intentions to leave" was added to the equations of "Time 2 intentions to leave" (Model 4), "Time 1 intentions to leave" became significant, while "interpersonal relationships" from the job readiness subscale again became significant. The adjusted R2 score became 0.513 . The outcome variable "Time 2 intentions to leave" explained $26 \%, 41 \%, 47 \%$, and $51 \%$ of the variance in Models 1, 2, 3, and 4, respectively.

\section{Discussion}

\section{Subjective health status}

Our results showed that the first time NGNs' "intentions to leave" substantially increased, it was their subjective health status, especially psychological distress, that was an important predictor. This reflects a previous study's indication that psychological distress among NGNs leads to their early resignation ${ }^{12)}$. Our findings are also in line with those of a related survey, which reported that $53 \%$ of 66 advanced treatment hospitals stated that the early resignation of NGNs would increase in the near future, and psychological distress would be a major cause of this ${ }^{11}$.

In terms of the psychological distress experienced by NGNs, a perceived lack of knowledge and support during the role transition from student nurse to staff nurse is a major cause of their anxiety ${ }^{35)}$. Our results suggested this, specifically in the correlation coefficients of psychological distress with job stressors and job readiness.

However, in the results of our longitudinal survey, psychological distress did not have a significant association with intentions to leave, while cumulative fatigue was the most significant factor, followed by "Time 1 intentions to leave". This reflects a previous study finding ${ }^{36)}$, which indicated that turnover was related to exhaustion, and nurses with low levels of exhaustion are considered to have a health status compatible with continuing work. 
Table 1. Demographic characteristics of the sample

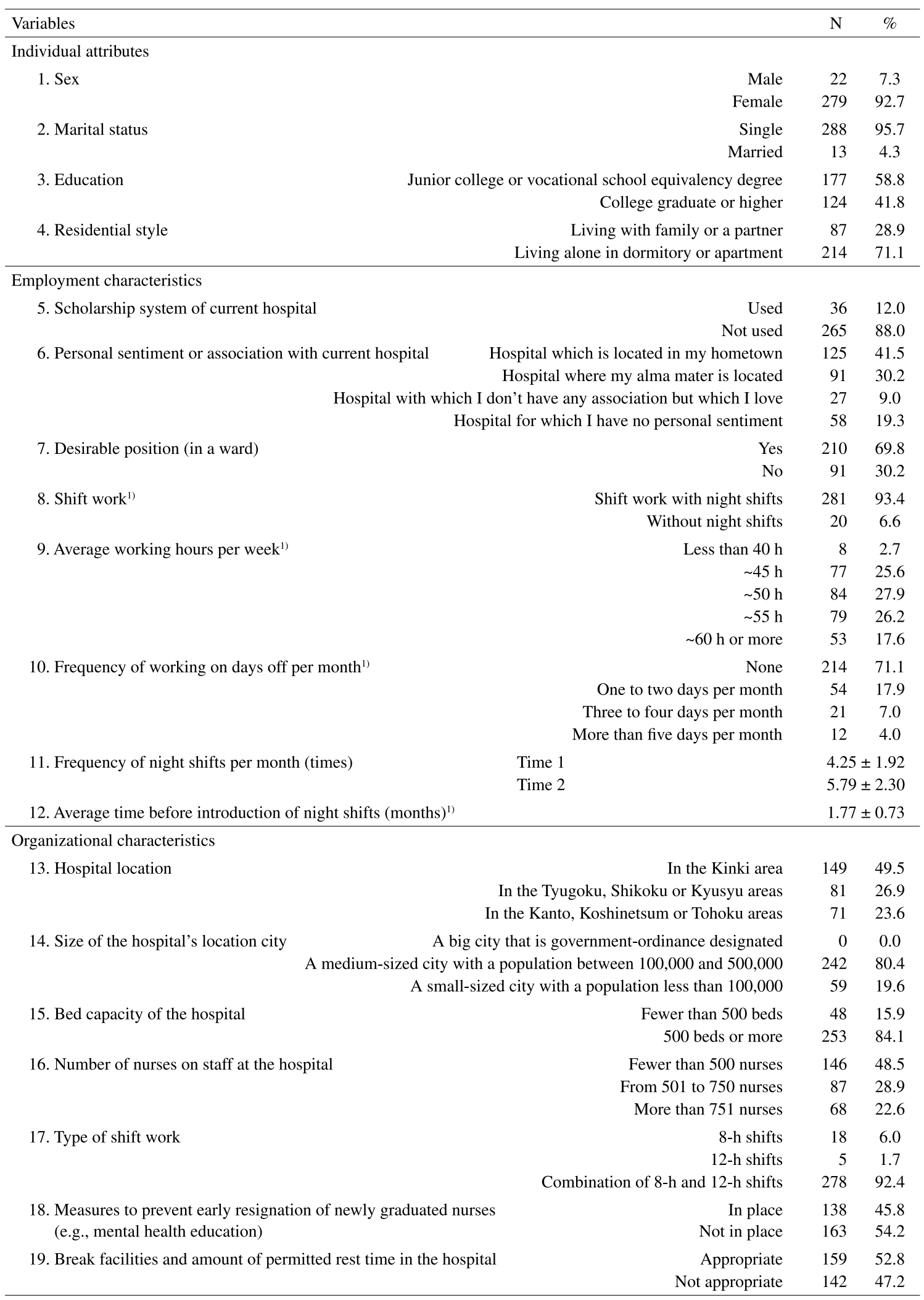

1) Data from Time 2

$\mathrm{n}=301$. 
Table 2. Descriptive statistics, Cronbach alphas, and results of $t$-tests of each variable at Time 1 and Time 2

\begin{tabular}{|c|c|c|c|c|c|c|c|c|c|c|}
\hline \multirow{2}{*}{ Variables } & \multirow{2}{*}{ Items } & \multicolumn{4}{|c|}{ Time 1} & \multicolumn{4}{|c|}{ Time 2} & \multirow{2}{*}{$t$ - $\operatorname{tes}^{1)}$} \\
\hline & & Mean & SD & Range & Cronbach alphas & Mean & SD & Range & Cronbach alphas & \\
\hline \multicolumn{11}{|l|}{ Job readiness } \\
\hline Basic nursing skills and abilities ${ }^{2}$ & 6 & 13.46 & 2.69 & $6-21$ & 0.75 & & & & & \\
\hline Interpersonal relationships ${ }^{2)}$ & 4 & 10.54 & 1.76 & $5-16$ & 0.75 & & & & & \\
\hline Practical clinical expertise and confidence ${ }^{2)}$ & 8 & 17.33 & 3.49 & $8-27$ & 0.79 & & & & & \\
\hline Being personally suited for nursing work ${ }^{2)}$ & 3 & 7.63 & 1.76 & $3-12$ & 0.62 & & & & & \\
\hline \multicolumn{11}{|l|}{ JCQ-22 } \\
\hline Psychological demand $d^{3)}$ & 5 & 37.35 & 4.81 & $27-48$ & 0.61 & 37.14 & 4.98 & $23-48$ & 0.33 & \\
\hline Job control ${ }^{3)}$ & 9 & 68.88 & 6.91 & $38-88$ & 0.41 & 67.57 & 7.45 & $28-90$ & 0.48 & $* *$ \\
\hline Supervisor support ${ }^{3)}$ & 4 & 12.57 & 2.10 & $6-16$ & 0.89 & 11.81 & 2.01 & $4-16$ & 0.88 & $* * *$ \\
\hline Coworker support ${ }^{3)}$ & 4 & 12.24 & 1.99 & $6-16$ & 0.83 & 11.91 & 1.78 & $4-16$ & 0.78 & $* *$ \\
\hline \multicolumn{11}{|l|}{ Subjective health status } \\
\hline GHQ-12 & 12 & 21.71 & 4.90 & $10-36$ & 0.82 & 19.15 & 3.71 & $8-36$ & 0.64 & $* * *$ \\
\hline CF-13 & 13 & 26.86 & 5.18 & $14-39$ & 0.85 & 26.85 & 5.34 & $13-39$ & 0.88 & \\
\hline Intentions to leave & 6 & 12.21 & 5.34 & $6-24$ & 0.92 & 14.06 & 5.39 & $6-24$ & 0.93 & $* * *$ \\
\hline
\end{tabular}

${ }^{1)}$ Result of $t$-test between Time 1 score and Time 2 score. ${ }^{*} p<0.05 ;{ }^{*} p<0.01 ; * * *<0.001$.

${ }^{2)}$ Sub-scale of the job readiness scale, ${ }^{3)}$ Sub-scale of the JCQ-22 scale. $\mathrm{n}=301$.

Another previous study reported that fewer health problems among nurses were associated with working under $20 \mathrm{~h}$ a week ${ }^{37)}$. Meanwhile, in the present study, more than $40 \%$ of the study participants were working more than $51 \mathrm{~h}$ per week on average at Time 1 and Time 2. When considered alongside the national statistic that $18 \%$ of all nurses worked more than $24 \mathrm{~h}$ of overtime per month on average in 2005 ${ }^{38)}$, there is a clear tendency of long work hours among NGNs.

To address the situation of cumulative fatigue having an effect on intentions to leave among NGNs, it is desirable to conduct an assessment of their workload, shift allocation, and existing hospital measures regarding subjective health status. Also, in an intervention to reduce psychological distress, it would be desirable to provide NGNs with the opportunity to monitor and enhance their skills and knowledge at an early stage in educational institutes and hospitals ${ }^{39}$.

\section{Job stressors}

Our findings revealed that among the job stressors, lack of coworker support was consistently a particularly important predictor of intentions to leave, while lack of supervisor support was a more important predictor at Time 1 .

The present study's result that lack of supervisor support led to increased intentions to leave, especially at an early stage, coincided with the results of previous studies. It has been indicated that supervisors' management style and attitude may influence the level of support provided to NGNs and that these have an effect on their rate of resignation $\left.{ }^{4}, 10,19,35,40\right)$. Since there is also an indication that consideration on the part of managers direct- ly and positively affects the retention of staff nurses ${ }^{40)}$, hospital employers and managers need to understand how to exhibit a beneficial management style for the prevention of NGNs' early resignation.

In the present longitudinal survey, the lack of coworker support led to increased intentions to leave. This reflects the importance of coworker support as indicated by previous studies ${ }^{7,19,35)}$. Suzuki et al. (2006) reported a risk ratio of $2.29(p<0.01)$ times greater turnover for NGNs who indicated a lack of social support from peers ${ }^{7}$. Correspondingly, a previous survey reported that NGNs who begin jobs as coworkers at the same hospital and who support each other have the strongest and healthiest work ethic ${ }^{11}$.

Our results also suggest that there is a need to enforce support structures that consider the uniqueness of the nursing work culture. Two previous studies have indicated that compared with men, women react strongly and favorably to strong support structures ${ }^{37)}$ and more negatively to poor support structures after controlling for inherited genetic factors ${ }^{41)}$. Comparably, another study indicated that support from colleagues and senior staff is an appropriate measure to counteract stress within the nursing profession ${ }^{42)}$. In view of this, especially in nursing workplaces where the majority of workers are women, hospital employers need to intervene continually to increase and maintain the support of NGNs from colleagues and senior staff.

The significance of job control in our study results is supported by previous research ${ }^{43,44)}$. It also suggests that low job control affects young nurses' professional efficacy and increases their intentions to leave. On the other 
Table 3. Correlation coefficients of independent variables associated with intentions to leave at Time 1 and Time 2

\begin{tabular}{|c|c|c|c|c|c|c|c|c|c|c|c|c|}
\hline & Variables & (1) & (2) & & (3) & & (4) & & (5) & & (6) & \\
\hline (1) & Basic nursing skills and abilities & 1.000 & & & & & & & & & & \\
\hline (2) & Interpersonal relationships & $0.532 * * *$ & 1.000 & & & & & & & & & \\
\hline (3) & Practical clinical expertise and confidence & $0.570 * * *$ & 0.601 & $* * *$ & 1.000 & & & & & & & \\
\hline (4) & Being personally suited for nursing work & $0.356 * * *$ & 0.355 & $* * *$ & 0.414 & $* * *$ & 1.000 & & & & & \\
\hline (5) & Time 1 Psychological demand & $-0.269 * * *$ & -0.150 & $* *$ & -0.215 & $* * *$ & -0.320 & $* * *$ & 1.000 & & & \\
\hline (6) & Time 1 Job control & $0.212 * * *$ & 0.202 & $* * *$ & 0.180 & $* *$ & 0.256 & $* * *$ & 0.004 & & 1.000 & \\
\hline (7) & Time 1 Supervisor support & $0.144 *$ & 0.312 & $* * *$ & 0.158 & $* *$ & 0.305 & $* * *$ & -0.182 & $* *$ & 0.307 & $* * *$ \\
\hline (8) & Time 1 Coworker support & $0.247 * * *$ & 0.429 & $* * *$ & 0.237 & $* * *$ & 0.349 & $* * *$ & -0.178 & $* *$ & 0.398 & $* * *$ \\
\hline (9) & Time 1 GHQ-12 & $-0.348 * * *$ & -0.448 & $* * *$ & -0.472 & $* * *$ & -0.512 & $* * *$ & 0.368 & $* * *$ & -0.076 & \\
\hline (10) & Time $1 \mathrm{CF}-13$ & $-0.362 * * *$ & -0.424 & $* * *$ & -0.433 & $* * *$ & -0.477 & $* * *$ & 0.411 & $* * *$ & -0.090 & \\
\hline (11) & Time 1 Intentions to leave & $-0.258 * * *$ & -0.392 & $* * *$ & -0.273 & $* * *$ & -0.576 & $* * *$ & 0.297 & $* * *$ & -0.282 & $* * *$ \\
\hline (12) & Time 2 Psychological demand & $-0.146 *$ & -0.085 & & -0.171 & $* *$ & -0.135 & $*$ & 0.433 & $* * *$ & -0.051 & \\
\hline (13) & Time 2 Job control & $0.123 *$ & 0.183 & $* *$ & 0.131 & $*$ & 0.205 & $* * *$ & -0.094 & & 0.487 & $* * *$ \\
\hline (14) & Time 2 Supervisor support & 0.099 & 0.258 & $* * *$ & 0.113 & $*$ & 0.206 & $* * *$ & -0.203 & $* * *$ & 0.294 & $* * *$ \\
\hline (15) & Time 2 Co-worker support & $0.153 * *$ & 0.282 & $* * *$ & 0.115 & $*$ & 0.200 & $* * *$ & -0.165 & $* *$ & 0.271 & $* * *$ \\
\hline (16) & Time 2 GHQ-12 & $-0.214 * * *$ & -0.151 & $* *$ & -0.148 & $*$ & -0.224 & $* * *$ & 0.208 & $* * *$ & -0.035 & \\
\hline (17) & Time 2 CF- 13 & $-0.260 * * *$ & -0.261 & $* * *$ & -0.286 & $* * *$ & -0.343 & $* * *$ & 0.336 & $* * *$ & -0.114 & $*$ \\
\hline (18) & Time 2 Intentions to leave & $-0.244 * * *$ & -0.263 & $* * *$ & -0.243 & $* * *$ & -0.504 & $* * *$ & 0.273 & $* * *$ & -0.279 & $* * *$ \\
\hline
\end{tabular}

$$
\text { Variables }
$$

(7)

(8)

(9)

(10)

(11)

(12)

(1) Basic nursing skills and abilities

(2) Interpersonal relationships

(3) Practical clinical expertise and confidence

(4) Being personally suited for nursing work

(5) Time 1 Psychological demand

(6) Time 1 Job control

(7) Time 1 Supervisor support

(8) Time 1 Coworker support

(9) Time 1 GHQ-12

(10) Time 1 CF-13

(11) Time 1 Intentions to leave

(12) Time 2 Psychological demand

(13) Time 2 Job control

(14) Time 2 Supervisor support

(15) Time 2 Co-worker support

(16) Time 2 GHQ-12

(17) Time 2 CF-13

(18) Time 2 Intentions to leave

\begin{tabular}{|c|c|c|c|c|c|c|c|c|c|c|c|}
\hline \multicolumn{12}{|l|}{1.000} \\
\hline 0.754 & $* * *$ & 1.000 & & & & & & & & & \\
\hline-0.222 & $* * *$ & -0.290 & $* * *$ & 1.000 & & & & & & & \\
\hline-0.287 & $* * *$ & -0.307 & $* * *$ & 0.748 & $* * *$ & 1.000 & & & & & \\
\hline-0.496 & $* * *$ & -0.513 & $* * *$ & 0.524 & $* * *$ & 0.532 & $* * *$ & 1.000 & & & \\
\hline-0.052 & & -0.055 & & 0.169 & $* *$ & 0.202 & $* * *$ & 0.166 & $* *$ & 1.000 & \\
\hline 0.232 & $* * *$ & 0.277 & $* * *$ & -0.128 & $*$ & -0.100 & & -0.247 & $* * *$ & -0.165 & $* *$ \\
\hline 0.445 & $* * *$ & 0.426 & $* * *$ & -0.194 & $* * *$ & -0.265 & $* * *$ & -0.361 & $* * *$ & -0.155 & $* *$ \\
\hline 0.377 & $* * *$ & 0.462 & $* * *$ & -0.186 & $* *$ & -0.268 & $* * *$ & -0.346 & $* * *$ & -0.098 & \\
\hline-0.043 & & -0.036 & & 0.325 & $* * *$ & 0.345 & $* * *$ & 0.195 & $* * *$ & 0.204 & $* * *$ \\
\hline-0.163 & $* *$ & -0.196 & $* * *$ & 0.491 & $* * *$ & 0.579 & $* * *$ & 0.388 & $* * *$ & 0.353 & $* * *$ \\
\hline-0.357 & $* * *$ & -0.383 & $* * *$ & 0.379 & $* * *$ & 0.434 & $* * *$ & 0.645 & $* * *$ & 0.259 & $* * *$ \\
\hline (13) & & (14) & & (15) & & (16) & & (17) & & & \\
\hline
\end{tabular}

(1) Basic nursing skills and abilities

(2) Interpersonal relationships

(3) Practical clinical expertise and confidence

(4) Being personally suited for nursing work

(5) Time 1 Psychological demand

(6) Time 1 Job control

(7) Time 1 Supervisor support

(8) Time 1 Coworker support

(9) Time 1 GHQ-12

(10) Time 1 CF-13

(11) Time 1 Intentions to leave

(12) Time 2 Psychological demand

(13) Time 2 Job control

(14) Time 2 Supervisor support

(15) Time 2 Co-worker support

(16) Time 2 GHQ-12

(17) Time 2 CF-13

(18) Time 2 Intentions to leave

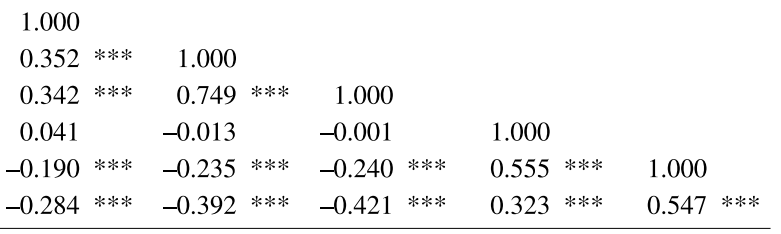

Pearson correlation coefficient. ${ }^{*} p<0.05 ;{ }^{* *} p<0.01 ;{ }^{* * *} p<0.001$. $\mathrm{n}=301$. 
Table 4. The results of hierarchical multiple regression analysis for Time 1 intentions to leave

\begin{tabular}{|c|c|c|c|c|c|c|}
\hline & $\begin{array}{c}\text { Model } 1 \\
B\end{array}$ & & $\begin{array}{c}\text { Model } 2 \\
B\end{array}$ & & $\begin{array}{c}\text { Model } 3 \\
B\end{array}$ & \\
\hline \multicolumn{7}{|l|}{ Factors which happened before work } \\
\hline \multicolumn{7}{|l|}{ Job readiness } \\
\hline Basic nursing skills and abilities & 0.026 & & 0.042 & & 0.046 & \\
\hline Interpersonal relationships & -0.271 & $* * *$ & -0.167 & ** & -0.112 & * \\
\hline Practical clinical expertise and confidence & 0.095 & & 0.050 & & 0.103 & \\
\hline Being personally suited for nursing work & -0.523 & $* * *$ & -0.381 & *** & -0.291 & $* * *$ \\
\hline \multicolumn{7}{|l|}{ Factors which happened when work began } \\
\hline \multicolumn{7}{|l|}{ Employment and organizational characteristics $\left.{ }^{2}\right)$} \\
\hline Bed capacity of the hospital ${ }^{3)}$ & & & -0.153 & ** & -0.158 & $* * *$ \\
\hline Mental health education as a measure to prevent early resignation ${ }^{4)}$ & & & 0.033 & & 0.034 & \\
\hline Personal sentiment or association with current hospital ${ }^{5)}$ & & & -0.036 & & -0.012 & \\
\hline Break facilities and amount of permitted rest time in the hospital ${ }^{6)}$ & & & 0.070 & & 0.046 & \\
\hline Shift work ${ }^{7}$ & & & 0.061 & & 0.060 & \\
\hline Working hours $^{8)}$ & & & 0.008 & & -0.020 & \\
\hline Frequency of working on days off ${ }^{9)}$ & & & 0.045 & & 0.066 & \\
\hline \multicolumn{7}{|l|}{ Time $1 \mathrm{JCQ}-22$} \\
\hline Psychological demand & & & 0.083 & & 0.023 & \\
\hline Job control & & & -0.081 & & -0.109 & * \\
\hline Supervisor support & & & -0.152 & * & -0.149 & * \\
\hline Coworker support & & & -0.144 & * & -0.130 & * \\
\hline \multicolumn{7}{|l|}{ Work adjustment factors which influence the outcome } \\
\hline \multicolumn{7}{|l|}{ Time 1 Subjective health status and intentions to leave } \\
\hline GHQ-12 & & & & & 0.183 & ** \\
\hline CF-13 & & & & & 0.142 & * \\
\hline$R$ & 0.639 & $* * *$ & 0.733 & *** & 0.763 & $* * *$ \\
\hline$R^{2}$ & 0.408 & & 0.538 & & 0.582 & \\
\hline Adjusted $R^{2}$ & 0.394 & & 0.508 & & 0.553 & \\
\hline $\mathrm{R}^{2}$ change & 0.408 & & 0.129 & & 0.045 & \\
\hline F change & 28.901 & $* * *$ & 7.157 & $* * *$ & 15.072 & $* * *$ \\
\hline \multicolumn{7}{|c|}{$\begin{array}{l}\text { 1) Hierarchical multiple regression analysis adjusted for individual attributes }\left(\mathrm{e} . \mathrm{g} ., \text { sex, age, and education). }{ }^{2)} \text { Each variable of }\right. \\
\text { employment and organizational characteristics shows a significant correlation coefficient with the outcome variable. }{ }^{3)} 1=\text { More than } \\
501 \text { beds, } 0=\text { Other. }{ }^{4)} 1=\text { In place, } 0=\text { Not in place. }{ }^{5)} 1=\text { Hospital for which } \mathrm{I} \text { have sentiment or association, } 0=\text { Hospital for which } \\
\text { I have no personal sentiment. } 0=\text { adequate, } 1=\text { Inadequate. }{ }^{7)} 1=\text { With night shifts, } 0=\text { Without. }{ }^{8)} 1=\text { More than } 56 \mathrm{~h} \text { per week on } \\
\text { average, } 0=\text { Less than } 55 \text { her week on average. }{ }^{9)} 0=\text { None, } 1=\text { More than } 1 \mathrm{~d} / \text { month. } \\
{ }^{*} p<0.05 ;{ }^{* *} p<0.01 ;{ }^{* *} p<0.001 . \\
\mathrm{n}=301 .\end{array}$} \\
\hline
\end{tabular}

hand, there has been an indication that occupational stress assessment tools like the Job Content Questionnaire (JCQ) that are based on the JD-C Model usually do not reveal enough details about the specific work environment of clinical nurses ${ }^{45}$. Thus further examination using a similar scale is necessary in the future.

\section{Job readiness and organizational characteristics}

"Being personally suited for nursing work" was an important predictor of NGNs' intentions to leave and consistently suggested some problems leading to the early resignation of NGNs in Japan. A previous survey indicated that NGNs may quit their jobs if they are often grappling with career choices ${ }^{2}$. This is because there is an overemphasis on derived scores in making career choices at universities in Japan. This may also cause a gap between the nurses' preconceptions and the reality of the job.

There is an indication that the greater the similarity between job requirements and vocational interests, the lower the turnover rate is ${ }^{4)}$. Thus, regardless of the students' level of motivation in choosing nursing, faculty administrations need to provide support to student nurses. In turn, this may improve their motivation for nursing work and may help prevent their early resignation.

The significance of "interpersonal relationships" in our study results may indicate that NGNs who are not good at communicating with their coworkers tend not to seek help, and this increases their job dissatisfaction. This reflects a previous finding that seeking social support is a key coping strategy for dealing with the stressors brought by the transition from student to professional nurse, and it thus decreased turnover intent ${ }^{46)}$. 
Table 5. Results of hierarchical multiple regression analysis for Time 2 intentions to leave

\begin{tabular}{|c|c|c|c|c|c|c|c|c|}
\hline & $\begin{array}{c}\text { Model } 1 \\
B\end{array}$ & & $\begin{array}{c}\text { Model } 2 \\
B\end{array}$ & & $\begin{array}{c}\text { Model } 3 \\
B\end{array}$ & & $\begin{array}{c}\text { Model } 4 \\
B\end{array}$ & \\
\hline \multicolumn{9}{|l|}{ Factors which happened before work } \\
\hline \multicolumn{9}{|l|}{ Job readiness } \\
\hline Basic nursing skills and abilities & -0.054 & & -0.048 & & -0.022 & & -0.035 & \\
\hline Interpersonal relationships & -0.079 & & 0.036 & & 0.074 & & 0.117 & $*$ \\
\hline Practical clinical expertise and confidence & 0.040 & & -0.014 & & 0.021 & & 0.001 & \\
\hline Being personally suited for nursing work & -0.470 & $* * *$ & -0.327 & $* * *$ & -0.245 & $* * *$ & -0.137 & $*$ \\
\hline \multicolumn{9}{|l|}{ Factors which happened when work began } \\
\hline \multicolumn{9}{|l|}{ Employment and organizational characteristics ${ }^{2}$} \\
\hline Bed capacity of the hospital ${ }^{3)}$ & & & -0.184 & $* * *$ & -0.173 & $* *$ & -0.115 & * \\
\hline Mental health education as a measure to prevent early resignation ${ }^{4)}$ & & & 0.007 & & -0.005 & & -0.007 & \\
\hline Personal sentiment or association with current hospital ${ }^{5)}$ & & & -0.073 & & -0.031 & & -0.030 & \\
\hline Break facilities and amount of permitted rest time in the hospital ${ }^{6}$ & & & 0.114 & * & 0.077 & & 0.054 & \\
\hline Shift work ${ }^{7)}$ & & & -0.017 & & -0.020 & & -0.011 & \\
\hline Working hours $^{8)}$ & & & 0.000 & & -0.029 & & -0.017 & \\
\hline Frequency of working on days off ${ }^{9)}$ & & & 0.036 & & 0.038 & & 0.033 & \\
\hline \multicolumn{9}{|l|}{ Mean score for JCQ-22 } \\
\hline Psychological demand & & & 0.084 & & 0.019 & & 0.019 & \\
\hline Job control & & & -0.114 & * & -0.129 & $*$ & -0.107 & $*$ \\
\hline Supervisor support & & & -0.048 & & -0.039 & & 0.012 & \\
\hline Coworker support & & & -0.256 & $* * *$ & -0.235 & $* *$ & -0.189 & * \\
\hline \multicolumn{9}{|l|}{ Work adjustment factors which influence the outcome } \\
\hline \multicolumn{9}{|l|}{ Mean score for subjective health status } \\
\hline GHQ-12 & & & & & 0.056 & & 0.010 & \\
\hline $\mathrm{CF}-13$ & & & & & 0.273 & $* * *$ & 0.240 & $* * *$ \\
\hline Time 1 intentions to leave & & & & & & & 0.322 & $* * *$ \\
\hline$R$ & 0.526 & $* * *$ & 0.670 & $* * *$ & 0.709 & $* * *$ & 0.740 & $* * *$ \\
\hline$R^{2}$ & 0.277 & & 0.449 & & 0.502 & & 0.547 & \\
\hline Adjusted $R^{2}$ & 0.260 & & 0.414 & & 0.467 & & 0.513 & \\
\hline $\mathrm{R}^{2}$ change & 0.277 & & 0.172 & & 0.053 & & 0.045 & \\
\hline$F$ change & 16.043 & & 8.001 & & 14.982 & & 27.713 & \\
\hline
\end{tabular}

1) Hierarchical multiple regression analysis adjusted for individual attributes (e.g., sex, age, and education). ${ }^{2)}$ Each variable of employment and organizational characteristics shows a significant correlation coefficient with the outcome variable. ${ }^{3)} 1=$ More than 501 beds, $0=$ Other. ${ }^{4)} 1=$ In place, $0=$ Not in place. ${ }^{5)} 1=$ Hospital for which $\mathrm{I}$ have sentiment or association, $0=$ Hospital for which $\mathrm{I}$ have no personal sentiment. ${ }^{6)} 0=$ Adequate, $1=$ Inadequate. ${ }^{7)} 1=$ With night shifts, $0=$ Without. ${ }^{8)} 1=$ More than $56 \mathrm{~h}$ per week on average, $0=$ Less than $55 \mathrm{~h}$ per week on average. ${ }^{9)} 0=$ None, $1=$ More than $1 \mathrm{~d} /$ month.

${ }^{*} p<0.05 ;{ }^{* *} p<0.01 ; * * * p<0.001$.

$\mathrm{n}=301$.

In our results, although lower hospital bed capacity was one of the predictors of intentions to leave, education and holding a desired ward position were not predictors. This is in disagreement with the results of a previous study of NGN turnover ${ }^{7}$. In terms of the relationship between hospital bed capacity and actual intentions to leave, it is possible that there is a background of organizational problems in lower-capacity hospitals. Further examination of this issue is needed.

Limitations and significance of this study and future research directions

This study has some limitations. First, this study did not employ a random sampling method, and the selection of participants was restricted to NGNs in eight advanced treatment hospitals. While our study used multiple levels of data (hospital size, hospital location, and organizational characteristics), the hospitals with the majority of participants had a capacity of 500 beds or more and were located in medium-sized cities. Our results may have revealed problems that are unique to the particular hospitals that agreed to cooperate in our research, and this may result in problems with conducting a cluster analysis. In the future, it would be useful to do a large-scale survey of various sizes of hospitals located in small- and large-sized cities, and conduct a cluster analysis. Second, the reliability and validity of the 21 -item job readiness scale that we developed would benefit from further testing in the future. Third, since the outcome variables in this study were based on self-reported data, further stud- 
ies using more objective measures such as actual turnover rates would be helpful.

Regarding the significance of the results of this longitudinal study, most of the previously published studies of NGNs' intentions to leave were only cross-sectional. Very little longitudinal research has been done in Japan to examine the effects of subjective health status, job stressors, and job readiness on intentions to leave among NGNs during their career. Furthermore, our study had high coefficients of determination (adjusted R-squared) for "intentions to leave" (see Tables 4 and 5). Therefore, although our study may have some limitations, our approach has yielded meaningful insights into nursing turnover at advanced treatment hospitals in Japan.

\section{Conclusion}

This study used a longitudinal design to analyze the predictors of intentions to leave among NGNs early in their career. The results are summarized as follows:

1. Subjective health status factors influenced intentions to leave, independently of demographic factors, job stressors, and job readiness. As well, while psychological distress was a more important predictor of intentions to leave than cumulative fatigue in the cross-sectional survey at Time 1, the longitudinal survey results showed that cumulative fatigue was a much more important predictor of intentions to leave.

2. Among the job stressors, coworker support was consistently a particularly important predictor of intentions to leave, while supervisor support was a more important predictor at Time 1.

3. "Being personally suited for nursing work", which was one of the job-readiness subscales, was found to independently and consistently influence newly graduated nurses' intentions to leave.

These results can be of significant help for hospital employers and managers to understand ways to prevent the early resignation of NGNs.

\section{Acknowledgements}

This study was supported by a Grant-in-Aid for Scientific Research from the Japan Society for the Promotion of Science (\#19592552).

\section{References}

1) Ministry of Health, Labour and Welfare. The sixth result of study concerning supply-demand outlook of nursing staff. http://www.mhlw.go.jp/shingi/2005/12/s1226-5.html. Accessed October 27, 2008 (in Japanese).

2) Japanese Nursing Association Nurse Center (2006) The report of measure for early retirement of newly graduated nurses in 2005, 1-33, Japanese Nursing Association Central Nurse Center, Tokyo (in Japanese).

3) Allen DG (2004) Explaining the link between turnover intentions and turnover. In: Innovative theory and empirical research on employee turnover, Griffeth RHP (Ed.) Information age publishing, Connecticut.

4) Mobley WH (1982) Employee turnover: causes, consequences, and control, 1-185, Addison-Wesley Publishing, Massachusetts.

5) MorBark E, Nissly JA, Levin A (2001) Antecedents to retention and turnover among child welfare, social work, and other human service employees: what can we learn from past research? A reveiw and metaanalysis. Soc Serv Rev 75, 625-61.

6) Beecroft PC, Kunzman L, Krozek C (2001) RN internship: outcomes of a one-year pilot program. J Nurs Adm 31, 575-82.

7) Suzuki E, Itomine I, Kanoya Y, Katsuki T, Horii S, Sato C (2006) Factors affecting rapid turnover of novice nurses in university hospitals. J Occup Health 48, 49-61.

8) Alexander JA, Lichtenstein R, Oh HJ, Ullman E (1998) A causal model of voluntary turnover among nursing personnel in long-term psychiatric settings. Res Nurs Health 21, 415-27.

9) Koslowsky M, Marom M (2004) Stress measures as predictors of information to leave and turnover. Innovative theory and empirical research on employee turnover, 83-104, Information age publishing, Conneticut.

10) Coomber B, Barriball KL (2007) Impact of job satisfaction components on intent to leave and turnover for hospital-based nurse: a review of the research literature. Int J Nurs Stud 44, 297-314.

11) Japanese Nursing Association Nurse Center (2005) The survey report of actual condition of early retirement among newly graduated nurses in 2004. Japanese Nursing Association Central Nurse Center, Tokyo (in Japanese).

12) Mizuta M, Kousaka R, Tsuji S, Nakano M, Inoue J (2004) The degree of psychological distress and turnover wish among new graduate nurses. Bulletin of Nursing College, Wakayama Medical University 7, 21-7 (in Japanese with English abstract).

13) Bowles C, Candela L (2005) First job experiences of recent $\mathrm{RN}$ graduates: improving the work environment. J Nurs Adm 35, 130-7.

14) Higashiguchi $K$, Morikawa $Y$, Miura $K$, Nishijo $M$, Tabata M, Ishizaki M, Nakagawa H (1999) Burnout and related factors among hospital nurses. J Occup Health 41, 215-24.

15) Kawano Y (2008) Association of job-related stress factors with psychological and somatic symptoms among Japanese hospital nurses: effect of departmental environment in acute care hospitals. J Occup Health 50, 79-85.

16) Mcneely E (2005) The consequences of job stress for nurses' health: time for a check-up. Nurs Outlook 53, 
291-9.

17) Shen HC, Cheng Y, Tsai PJ, Lee SH, Guo YL (2005) Occupational stress in nurses in psychiatric institutions in Taiwan. J Occup Health 47, 218-25.

18) Kramer M (1974) Reality shock-Why nurses leave nursing, 1-249, Mosby, Saint Louis.

19) Lavoie-Tremblay M, O'Brien-Pallas L, Gelinas C, Desforges N, Marchionni C (2008) Addressing the turnover issue among new nurses from a generational viewpoint. J Nurs Manag 16, 724-33.

20) Carroll TL (2005) Stressful life events among new nurses: implications for retaining new graduates. Nurs Adm Q 29, 292-6.

21) Scott ES, Engelke MK, Swanson M (2008) New graduate nurse transitioning: necessary or nice? Appl Nurs Res 21, 75-83.

22) Parry J (2008) Intention to leave the profession: antecedents and role in nurse turnover. J Adv Nurs 64, 157-67.

23) Matsushita Y, Shibata K (2004) Factors in early retirement of nurses newly graduated from college: motives of the selection of occupation and related factors half a year after employment. Bulletin of Yamanashi College of Nursing 6, 65-72 (in Japanese).

24) Japanese Nursing Association. News release May 26th 2007. http://www.nurse.or.jp/home/opinion/newsrelease/ 2006pdf/20070326-02.pdf. Accessed October 27, 2008 (in Japanese).

25) Health Labor and Welfare Ministry Health Policy Bureau Department of Nursing. Attainment targets and guideline index for staff training of new nursing staff. http://www.mhlw.go.jp/topics/2004/12/dl/tp1215-3a.pdf Accessed October 27, 2008 (in Japanese).

26) Hirayama A, Shimanouchi $S$, Ando $T$, Kusama $T$, Sasada M, Sato E, Sato R (2004) Goal attainment level for enhancement of nursing practice ability when graduating university education. Study committee concerning what should be of nursing study education, 1-47, Health Labor and Welfar Ministry, Tokyo (in Japanese).

27) Karasek R, Theorell T (1990) Healty work: stress, productivity, and the reconstruction of working life, 1-346, Basic Book, New York.

28) Kawakami N, Fujigaki Y (1996) Reliability and validity of the Japanese version of Job Content Questionnaire: replication and extension in computer company employees. Ind Health 34, 295-306.

29) Goldberg DP, GaterR, Sartorius N, Ustun TB, Piccinelli M, Gureje O, Rutter C (1997) The validity of two versions of the GHQ in the WHO study of mental illness in general health care. Psychol Med 27, 191-7.

30) Iwata N, Okuyama Y, Kawakami Y, Saito K (1998) The twelve-item General Health Questionnaire among Japanese workers. Environmental Science Hokkaido University 11, 1-10.

31) Kikukawa S, Kikukawa R (2006) Comparison of fatigue of staffs between sub-acute rehabilitation care unit and long term care unit. Sogo Rehabilitation 34, 897-902 (in Japanese).

32) Tei M, Yamazaki Y (2003) The effect of work and organizational characteristics on individual and organizational outcomes of an information service company. San Ei Shi 45, 20-30 (in Japanese with English abstract).

33) Tominaga M, Asakura T, Akiyama T (2007) The effect of micro and macro stressors in work organization characteristics on computer professionals' subjective health status and productive behavior in Japan. Ind Health 45, 474-86.

34) Feinstein AR (1996) Strategies of targeted algebraic methods. In: Multivariable analysis: an introduction, Feinstein AR (Ed.), 226, Yale University Press, New Haven.

35) Whitehead J (2001) Newly qualified staff nurses' perceptions of the role transition. Br J Nurs 10, 330-2, 334-9.

36) Shimizu T, Feng Q, Nagata S (2005) Relationship between turnover and burnout among Japanese hospital nurses. J Occup Health 47, 334-6.

37) Walters V, Lenton $R$, French $S$, Eyles J, Mayr J, Newbold B (1996) Paid work, unpaid work and social support: a study of the health of male and female nurses. Soc Sci Med 43, 1627-36.

38) Japanese Nursing Association. News release July 5th 2006. http://www.nurse.or.jp/home/opinion/newsrelease/ 2006pdf/20060705.pdf. Accessed October 27, 2008 (in Japanese).

39) Salt J, Cummings GG, Profetto-McGrath J (2008) Increasing retention of new graduate nurses: a systematic review of interventions by healthcare organizations. J Nurs Adm 38, 287-96.

40) Taunton RL, Boyle DK, Wooks CQ, Hansen HE, Bott MJ (1997) Manager leadership and retention of hospital staff nurses. West J Nurs Res 19, 206-26.

41) Kendler KS, Myers J, Prescott CA (2005) Sex differences in the relationship between social support and risk for major depression: a longitudinal study of oppositesex twin pairs. Am J Psychiatry 162, 250-6.

42) McVicar A (2003) Workplace stress in nursing: a literature review. J Adv Nurs 44, 633-42.

43) Seago JA (1996) Work group culture, stress, and hostility: correlations with organizational outcomes. J Nurs Adm 26, 39-47.

44) Shader K, Broome ME, Broome CD, West ME, Nash M (2001) Factors influencing satisfaction and anticipated turnover for nurses in an academic medical center. $\mathrm{J}$ Nurs Adm 31, 210-6.

45) Mori T, Kageyama T (1995) A cross-sectional survey on mental health and working environment of hospital nurses. San Ei Shi 37, 135-42 (in Japanese with English abstract).

46) Beecroft PC, Dorey F, Wenten M (2008) Turnover intention in new graduate nurses: a multivariate analysis. J Adv Nurs 62, 41-52. 